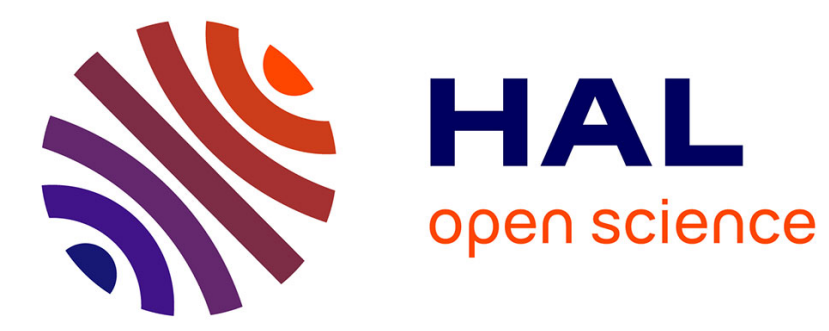

\title{
Proton transfer reactions of hydrazine-boranes
}

Aiko Adamson, Jean-Claude Guillemin, Peeter Burk

\section{To cite this version:}

Aiko Adamson, Jean-Claude Guillemin, Peeter Burk. Proton transfer reactions of hydrazine-boranes. Journal of Physical Organic Chemistry, 2015, 28 (4), pp.244-249. 10.1002/poc.3401 . hal-01133064

\section{HAL Id: hal-01133064 https://hal-univ-rennes1.archives-ouvertes.fr/hal-01133064}

Submitted on 31 Aug 2015

HAL is a multi-disciplinary open access archive for the deposit and dissemination of scientific research documents, whether they are published or not. The documents may come from teaching and research institutions in France or abroad, or from public or private research centers.
L'archive ouverte pluridisciplinaire HAL, est destinée au dépôt et à la diffusion de documents scientifiques de niveau recherche, publiés ou non, émanant des établissements d'enseignement et de recherche français ou étrangers, des laboratoires publics ou privés. 


\section{Proton Transfer Reactions of Hydrazine-boranes.}

Aiko Adamson*(a), Jean-Claude Guillemin ${ }^{(b)}$, Peeter Burk(a)

(a) Institute of Chemistry, University of Tartu, 14a Ravila St., 50411, Estonia

Fax: (+372) 7375570 adamson@ut.ee peeter.burk@ut.ee

(b) Institut des Sciences Chimiques de Rennes, Ecole Nationale Supérieure de Chimie de Rennes, CNRS, UMR 6226, 11 Allée de Beaulieu, CS 50837, 35708 Rennes Cedex 7, France

\section{Abstract}

Hydrazine-borane and hydrazine-diborane contain respectively 15.4 and 16.9 $w t \%$ of hydrogen and are potential materials for hydrogen storage. In this work we present the gas-phase complexation energies, acidities and basicities of hydrazineborane and hydrazine-bisborane calculated at MP2/6-311+G(d,p) level. We also report the release of dihydrogen from both protonated complexes (Ghydrazine-borane = $20.9 \mathrm{kcal} / \mathrm{mol}$ and Gidrazine-bisborane $=-27.2 \mathrm{kcal} / \mathrm{mol}$ ) which is much more exergonic than from analogues amine-boranes. The addition of the first $\mathrm{BH}_{3}$ to the hydrazine releases $17.1 \mathrm{kcal} / \mathrm{mol}$ and the second addition releases $15.8 \mathrm{kcal} / \mathrm{mol}$. The attachment of $\mathrm{BH}_{3}$ also increases the $\mathrm{N}-\mathrm{H}$ acidity of hydrazine by $46.3 \mathrm{kcal} / \mathrm{mol}$. It was found that the $\mathrm{B}-\mathrm{H}$ deprotonation leads to intramolecular rearrangement. The basicity values for hydrazine-borane and -bisborane are 180 and $172.8 \mathrm{kcal} / \mathrm{mol}$ respectively. For both complexes the protonation centres are located at the boron moiety. The protonated structure of hydrazine-bisborane is cyclic and can be described as $\mathrm{H}_{2}$ captured between a negatively charged $\mathrm{B}-\mathrm{H}$ hydrogen and positive boron $(\mathrm{B}-\mathrm{H} \cdot \bullet \mathrm{H} 2 \cdot \bullet \mathrm{B})$. Atoms in Molecules analysis is used to investigate bond paths in concerning structures.

Keywords: ab initio calculations, gas-phase, hydrazine, borane, complex, acidity, basicity, dihydrogen 


\section{Introduction}

Hydrazine is a well-known compound with many applications; for example it is used as rocket fuel and a precursor in polymer foam industry. It is toxic and dangerously unstable. The history of hydrazine complex with borane $\left(\mathrm{N}_{2} \mathrm{H}_{4} \cdot \cdot \mathrm{BH}_{3}\right)$ dates back more than 50 years since its synthesis and thermal decomposition were first described by Ricker and Goubeau. ${ }^{[1]}$ The addition of borane changes the properties of free hydrazine considerably and new possible applications for the resulting complex are being investigated. One of the important features is the decrease in the activation energy of the $\mathrm{H}_{2}$ release reaction ${ }^{[2]}$ and therefore it has been suggested as a potential hydrogen storage material. ${ }^{[3,4]}$ The hydrogen content in $\mathrm{N}_{2} \mathrm{H}_{4} \mathrm{BH}_{3}$ is very high (15.37 wt \%) and comparable to ammonia-borane (19.6 wt $\%)$.

Unlike ammonia-borane, the hydrazine-borane has uneven amount hydrogens atoms - four protic $\left(\mathrm{H}^{\delta^{+}}\right)$and three hydridic $\left(\mathrm{H}^{\delta^{-}}\right)$and it is hard to separate all the hydrogen by simple thermal treatment. One option is to add metal hydrides like $\mathrm{LiH}$ and it has been shown that such an approach improves the dihydrogen release from the obtained salt significantly. ${ }^{[3]}$ Temperatures about $150{ }^{\circ} \mathrm{C}$ are common in the $\mathrm{H}_{2}$ extraction process and in the case of hydrazine-borane the reaction can be controlled up to $200^{\circ} \mathrm{C}$. The bisborane complex is less stable towards the heating. High energy content of hydrazine becomes evident when applying the same treatment to hydrazine-bisborane, as the explosive decomposition is reported to start at temperatures about $160^{\circ} \mathrm{C} .{ }^{[3]}$

The dihydrogen release from neutral hydrazine-borane has also been studied computationally. Vinh-Son et al.[2] have found that the $\mathrm{N}_{2} \mathrm{H}_{4} \rightarrow \mathrm{N}_{2} \mathrm{H}_{2}+\mathrm{H}_{2}$ reaction is endothermic by $22.1 \mathrm{kcal} / \mathrm{mol}$ (for the trans conformer at the CCSD(T)/CBS limit at 0 $\mathrm{K})$ and the addition of $\mathrm{BH}_{3}$ fundamentally changes the thermochemistry. $\Delta \mathrm{H}$ value of $-4.7 \mathrm{kcal} / \mathrm{mol}$ was predicted for the $\mathrm{BH}_{3} \mathrm{NH}_{2} \mathrm{NH}_{2} \rightarrow \mathrm{BH}_{2} \mathrm{NHNH}_{2}+\mathrm{H}_{2}$ reaction.

Amine-boranes are analogues to hydrazine-boranes as they also contain the $\mathrm{N}-\mathrm{B}$ bond and they have gained significantly more attention. The hydrogen release reaction as well as intrinsic properties related to hydrogen storage, like gas-phase basicity and acidity have been studied. ${ }^{[5,6,7]}$ It has been found that complexation 
greatly alters the properties of amines, for example the acidity is enhanced by $30-50$ $\left.\mathrm{kcal} / \mathrm{mol}^{.}{ }^{7,}, 8\right]$ The protonation centre of such complexes is located on the boron moiety and the resulting structure can be described as $\mathrm{R}_{1} \mathrm{R}_{2} \mathrm{R}_{3} \mathrm{~N}-\mathrm{BH}_{2}{ }^{+} \bullet \bullet \mathrm{H}_{2} .^{[5,6]}$ The dihydrogen is connected to the remaining complex with S-shaped 3-centre-2-electron bonds and its removal is clearly an exergonic process. ${ }^{[5]}$ The Gibbs free energy change for the dihydrogen dissociation reaction for amine-boranes varies from -11 to $-5 \mathrm{kcal} / \mathrm{mol}$. This kind of protonated structure is common for protonated borane complexes - for example the protonated phosphine boranes are very similar and also exhibit the hydrogen releasing properties. ${ }^{[9]}$

In this work we present the results related to proton transfer reactions of hydrazine-borane $\left(\mathrm{N}_{2} \mathrm{H}_{4} \mathrm{BH}_{3}\right)$ and hydrazine-bisborane $\left(\mathrm{BH}_{3} \mathrm{~N}_{2} \mathrm{H}_{4} \mathrm{BH}_{3}\right)$. At the first glance the structures seem to be very similar to amine-boranes, but some properties related to proton transfer reactions are not, for example the energetics of the dihydrogen release reactions are drastically different. In the past, the electronic structure of neutral hydrazine-borane and hydrazine-bisborane have been investigated, ${ }^{[10,11]}$ in this work we also report the structure and interactions present in protonated and deprotonated species.

\section{Computational details}

The calculations were carried out using the GAUSSIAN 09 ${ }^{[12]}$ program package under standard conditions (298.15 $\mathrm{K}$ and $1 \mathrm{~atm})$. In our work we used $M P 2^{[13-17]}$ method with $6-311+G(d, p)^{[18-21]}$ basis set. $M P 2 / 6-311+G(d, p)$ is an adequate and relatively cheap method for calculating systems discussed in this study. For example in Ref 7 and Ref 8 acidity of ten similar systems - amine-boranes have been calculated with $G 4$ and MP2/6-311+G(d,p) methods and the mean absolute error between the results is under $1 \mathrm{kcal} / \mathrm{mol}$. A full conformational search was done for each species and vibrational analyses for zero-point energies, and thermal corrections were performed. All stationary points were found to be true minima (NImag=0). For protonated and deprotonated species all possible protonation and deprotonation centres were investigated and only the most stable structures were used. For a free proton, the free energy value of $0.01 \mathrm{au}$. (ca. $627.5 \mathrm{kcal} / \mathrm{mol}$ ) was used; derived from statistical thermodynamics. In the case of complexation 
energies and dihydrogen removal reaction, basis set superposition error (BSSE) was calculated using the counterpoise method of Boys and Bernardi. ${ }^{[22]}$ The BSSE estimations for MP2/6-311+G(d,p) calculations were quite constant, approximately 4$5 \mathrm{kcal} / \mathrm{mol}$ for complexation reactions and about $2 \mathrm{kcal} / \mathrm{mol}$ for dihydrogen removal. We use Gibbs free energy changes for all studied reactions in this work. Calculated enthalpies can be found in the supplementary information.

To investigate the electronic structure of the complexes in more detail, we performed Bader's Atoms in Molecules (AIM) analysis. ${ }^{[23,24]}$ It allows us to track electron density between atoms and therefore draw conclusions about the character and the strength of the bonds present in a molecule. Two important characteristics of the AIM analysis are the electron density $(\rho)$ and the laplacian of the electron density $\left(\nabla^{2} \rho\right)$ in the bond critical point $(\mathrm{BCP}$, where the electron density is minimal along the bond path). Electron density at the BCP indicates the amount of electrons involved in the bond formation and higher density refers to a stronger bond. The laplacian of the electron density in the BCP characterizes the curvature of the electron density distribution and is an indicator of bond covalency. Negative values generally refer to more covalent interactions.

\section{Results and discussion}

It is known that hydrazine-borane and hydrazine-bisborane are both stable solids at normal temperatures. Our computations confirm that both complexes are also stable in the gas-phase and our calculated Gibbs free energy changes for the following complexation reactions are as follows:

$$
\begin{gathered}
\mathrm{N}_{2} \mathrm{H}_{4}+\mathrm{BH}_{3} \rightarrow \mathrm{NH}_{2} \mathrm{NH}_{2}-\mathrm{BH}_{3} \quad \Delta \mathrm{G}=-17.1 \mathrm{kcal} / \mathrm{mol} \\
\mathrm{NH}_{2} \mathrm{NH}_{2}-\mathrm{BH}_{3}+\mathrm{BH}_{3} \rightarrow \mathrm{H}_{3} \mathrm{~B}-\mathrm{NH}_{2} \mathrm{NH}_{2}-\mathrm{BH}_{3} \quad \Delta \mathrm{G}=-15.8 \mathrm{kcal} / \mathrm{mol}
\end{gathered}
$$

The energy released in the first and second complexation step is very close, which allows us to conclude that the first addition of $\mathrm{BH}_{3}$ has very little effect to the electron donating ability of the second nitrogen. Both values are also comparable to complexation values of amine-boranes. For example $\Delta G$ for unsubstituted amineborane is $-14.1 \mathrm{kcal} / \mathrm{mol}$ and values for substituted complexes vary from -15 to -22 
$\mathrm{kcal} / \mathrm{mol}$, if we leave aside phenyl substituted amine-borane with an exceptionally low stability. ${ }^{[8]}$

\section{Deprotonation and gas-phase acidity}

Gas-phase acidity (GA) is defined as the Gibbs free energy change for the reversible deprotonation reaction. For hydrazine-borane and hydrazine-bisborane the theoretical deprotonation reactions would be as follows:

$$
\begin{gathered}
\mathrm{N}_{2} \mathrm{H}_{7} \mathrm{~B} \leftrightarrows \mathrm{N}_{2} \mathrm{H}_{6} \mathrm{~B}^{-}+\mathrm{H}^{+} \\
\mathrm{N}_{2} \mathrm{H}_{10} \mathrm{~B}_{2} \leftrightarrows \mathrm{N}_{2} \mathrm{H}_{10} \mathrm{~B}_{2}{ }^{-}+\mathrm{H}^{+}
\end{gathered}
$$

There are three possible different deprotonation centres in $\mathrm{N}_{2} \mathrm{H}_{7} \mathrm{~B}$ and two in $\mathrm{N}_{2} \mathrm{H}_{10} \mathrm{~B}_{2}$. The enthalpies and Gibbs free energies as well as relative energies and corresponding acidity values for all the deprotonation centres for both complexes are presented in Table 1. Our computations show, that the removal of proton from $\mathrm{BH}_{3}$ initiates intramolecular rearrangements leading to the destruction of the complex. The dissociated structures (result of $\mathrm{B}-\mathrm{H}$ deprotonation) are clearly energetically more favourable than the $\mathrm{N}-\mathrm{H}$ reversibly deprotonated species. The dissociated structures are presented in Figures 1 and 2 . The gap between the dissociated structure and the most favoured reversibly deprotonated structure (which corresponds to the $\mathrm{N}-\mathrm{H}$ acidity centre on nitrogen interacting with $\mathrm{BH}_{3}$ ) is $37.2 \mathrm{kcal} / \mathrm{mol}$ for hydrazine-borane and $36.4 \mathrm{kcal} / \mathrm{mol}$ for hydrazine-bisborane.

Since the B-H deprotonation leads to irreversible rearrangements resulting in energetically favourable structures we cannot calculate the true acidity for that deprotonation centre. Comparing the reactions resulting in "broken" deprotonated hydrazine-borane (Figure 1) and hydrazine-bisborane (Figure 2) we see that the deprotonation for the latter is about $25 \mathrm{kcal} / \mathrm{mol}$ more favourable. One of the reasons is the additional $\mathrm{BH}_{3}$ in hydrazine-bisborane which helps to stabilize the negative charge left by the removal of proton. The NBO charges of neutral and deprotonated complexes are presented in Table 2 and although the absolute values of atomic charges are dependent on the method the trends are not and are therefore useful in discussing structural and reactivity. ${ }^{[25,26]}$ The NBO values show that the B-H 
deprotonated hydrazine-borane dissociates into ammonia and negatively charged $\mathrm{BH}_{2} \mathrm{NH}^{-}$while $\mathrm{B}-\mathrm{H}$ deprotonated hydrazine-bisborane dissociates into double bonded $\mathrm{BH}_{2} \mathrm{NH}_{2}$ and $\mathrm{BH}_{3} \mathrm{NH}_{2}$. Since both deprotonated species separate into two, the changes in atomic charges are considerable. The interaction distances between the ammonia and $\mathrm{BH}_{2} \mathrm{NH}^{-}$in deprotonated hydrazine-borane as well as between $\mathrm{BH}_{2} \mathrm{NH}_{2}$ and $\mathrm{BH}_{3} \mathrm{NH}_{2}$ in deprotonated hydrazine-bisborane are clearly longer than normal $\mathrm{N}$ $\mathrm{H}$ bonds (the $\mathrm{N}-\mathrm{H}$ interaction distance in hydrazine-borane is $1.95 \AA$ and $1.83 \AA$ in hydrazine-bisborane). The electron density at the BCP is also considerably lower (0.03 hydrazine-borane and 0.04 in hydrazine-bisborane) compared to the covalent $\mathrm{N}-\mathrm{H}$ bonds in ammonia (ca. 0.30 )

We have calculated the gas-phase acidity of free hydrazine to be 393.9 $\mathrm{kcal} / \mathrm{mol}$ and the addition of a $\mathrm{BH}_{3}$ increases the acidity of the $\mathrm{N}-\mathrm{H}$ group considerably. Attaching $\mathrm{BH}_{3}$ to the nitrogen involved in the acidity centre enhances the acidity by $46.3 \mathrm{kcal} / \mathrm{mol}$ and attaching $\mathrm{BH}_{3}$ to the farther nitrogen increases the proton donating ability by $24.7 \mathrm{kcal} / \mathrm{mol}$. With $\mathrm{BH}_{3}$ molecules added to both nitrogen we get the hydrazine-bisborane complex where the acidity of the $\mathrm{N}-\mathrm{H}$ centre is enhanced by $72.3 \mathrm{kcal} / \mathrm{mol}$. Based on these values it is evident that the $\mathrm{N}-\mathrm{H}$ group in hydrazine-bisborane is $26 \mathrm{kcal} / \mathrm{mol}$ more acidic than in the hydrazine-borane.

The $\mathrm{N}-\mathrm{H}$ acidity of hydrazine-borane is close to amine-boranes. For example the acidity calculated with MP2/6-311+G(d.p) method for methyl amine-borane is $349.5 \mathrm{kcal} / \mathrm{mol}$ and $347.3 \mathrm{kcal} / \mathrm{mol}$ for dimethyl amine-borane. The acidity of the $\mathrm{N}-\mathrm{H}$ group in hydrazine-bisborane $(321.6 \mathrm{kcal} / \mathrm{mol})$ is clearly higher than the most acidic studied amine-borane - phenyl amine-borane $(327.3 \mathrm{kca} / \mathrm{mol})$.

Since the B-H deprotonations are followed by intramolecular rearrangements the calculated acidity values do not give us information from which centre will the proton be actually removed. To estimate the probabilities of $\mathrm{N}-\mathrm{H}$ and $\mathrm{B}-\mathrm{H}$ deprotonations we have calculated the so-called vertical deprotonation energies (proton removal energies without geometry relaxation) for both $\mathrm{N}-\mathrm{H}$ and $\mathrm{B}-\mathrm{H}$ hydrogens. It was found that the vertical deprotonation in the case of hydrazineborane favours the $\mathrm{N}-\mathrm{H}$ acidity by $70 \mathrm{kcal} / \mathrm{mol}$ over the $\mathrm{B}-\mathrm{H}$ deprotonation and the result is similar for hydrazine-bisborane, as the removal of $\mathrm{N}-\mathrm{H}$ hydrogens is favoured by $77 \mathrm{kcal} / \mathrm{mol}$ over the $\mathrm{B}-\mathrm{H}$ hydrogens. We also used an approach where a dimer 
consisting of two complexes was constructed positioned in a way that the competing deprotonation centres were facing each other. Both acidity centres were deprotonated and one proton was placed in the line between nitrogen and boron. Several distances around the centre of the direct line between the $\mathrm{N}$ and $\mathrm{B}$ atoms were chosen and for each case the geometry was allowed to relax. In all cases the relaxation resulted in the formation of the $\mathrm{B}-\mathrm{H}$ bond. As a result we can conclude that the $\mathrm{N}-\mathrm{H}$ should be more favourable deprotonation centre.

\section{Gas-phase basicity}

Gas-phase Basicity (GB) is defined as the negative Gibbs free energy change for the reversible protonation reaction. For hydrazine-borane and hydrazinebisborane the protonation reactions are as follows:

$$
\begin{array}{ll}
\mathrm{NH}_{2} \mathrm{NH}_{2} \mathrm{BH}_{3}+\mathrm{H}^{+} \leftrightarrows \mathrm{NH}_{2} \mathrm{NH}_{2} \mathrm{BH}_{2}{ }^{+} \bullet \mathrm{H}_{2} & \mathrm{~GB}=183.0 \mathrm{kcal} / \mathrm{mol} \\
\mathrm{H}_{3} \mathrm{BNH}_{2} \mathrm{NH}_{2} \mathrm{BH}_{3}+\mathrm{H}^{+} \leftrightarrows \mathrm{H}_{3} \mathrm{BNH}_{2} \mathrm{NH}_{2} \mathrm{BH}_{2} \cdot \bullet \mathrm{H}_{2} & \mathrm{~GB}=172.8 \mathrm{kcal} / \mathrm{mol}
\end{array}
$$

For both complexes the favoured protonation site is clearly on the boron moiety and the resulting structures can be described as dihydrogen connected to the rest of the positively charged complex. The protonated structures together with bond paths obtained by Bader's AIM theory are presented in Figures 3 and 4 . We can see from the Figure 3 that in protonated hydrazine-borane the dihydrogen is connected to boron by a 3-centre-2-electron bond. Such curved bond paths are also present in amine-boranes, ${ }^{[5]}$ while in analogous phosphine-boranes the bond-paths are different. ${ }^{[9]}$ AIM analyses also shows that the interactions in $\mathrm{H}_{2} \bullet B$ moiety in amineboranes and hydrazine-borane are very similar. The $\rho$ value in the BCP of the curved $\mathrm{B}-\mathrm{H}_{\mathrm{H} 2}$ interaction is 0.084 in hydrazine-borane and 0.0853 in unsubstituted amineborane. This is also the case for the Laplacian of the electron density at the BCP's as the $\nabla^{2} \rho$ value in hydrazine-borane is 0.1310 and 0.1210 in amine-borane. ${ }^{[9]}$

It can be concluded that the different electronic structure of hydrazine compared to amines has very little effect to the basicity of the borane complex (compared to free $\mathrm{BH}_{3}, \mathrm{~GB}=133 \mathrm{kcal} / \mathrm{mol}$, the addition of Lewis base of course enhances the basicity greatly). The basicity value for hydrazine-borane is 183.0 
$\mathrm{kcal} / \mathrm{mol}$ and for ammonia-borane it is $185.4 \mathrm{kcal} / \mathrm{mol}^{[5]}$ (both values were obtained using MP2/6-311+G(d.p) method). Bulkier carbon based N-substitutions in amineboranes usually increase the basicity and small electron withdrawing groups have the opposite effect. ${ }^{[5]}$ The chloro substitution in the amine for example reduces the proton affinity of the complex by ca. $13 \mathrm{kcal}$ (G2MP2) and fluoro substitution reduces it by ca. $21 \mathrm{kcal} / \mathrm{mol}$ (G2MP2). ${ }^{[27,28]}$ If we presume that entropy terms for the reactions involving substituted and unsubstituted complexes are close, we can estimate the basicity difference to be comparable to proton affinity differences. The hydrazine also possesses the electron withdrawing abilities and thus reduces the proton accepting ability of the complex compared to ammonia-borane.

Although the basicity of hydrazine-borane differed very little from amineboranes, it is important that the second nitrogen provides an additional complexation centre and the attachment of the second $\mathrm{BH}_{3}$ supports the formation of a considerably different protonated structure. The additional link in the backbone of the species allows a formation of a cyclic structure. In the new structure the $\mathrm{H}_{2}$ is captured between positively charged boron and negatively charged hydrogen (charges are presented in Table 2). "Regular" protonated structure with two S-shaped interactions like in protonated hydrazine-borane also exists for hydrazine-bisborane, but it is about $3.6 \mathrm{kcal} / \mathrm{mol}$ less stable than the cyclic structure. If we compare the most favourable basicity centres of both species we can conclude that the bis complex is by $10 \mathrm{kcal} / \mathrm{mol}$ less basic compared to hydrazine-borane. Those values suggest that the additional complexation with $\mathrm{BH}_{3}$ decreases the basicity of hydrazine-borane about $13.6 \mathrm{kcal} / \mathrm{mol}$.

If we compare the bond paths in the protonated hydrazine-bisborane to the ones in hydrazine-borane we see that one of the curved $\mathrm{H}_{2} \bullet \mathrm{B}$ interactions is replaced by the new $\mathrm{B}-\mathrm{H} \cdot \bullet \mathrm{H}_{2}$ interaction involving the second borane moiety. According to AIM analyses the two $\mathrm{H}_{2} \bullet B$ interactions in hydrazine-borane are characterized by the distance of $1.44 \AA$ and electron density of 0.084 at the BCP. The new interaction in hydrazine-bisborane is weaker - it is longer (1.74 $\AA$ ) and the electron density at the BCP is smaller (0.023).

The structure of protonated hydrazine-bisborane is similar to the molecular tweezer like structures of some amine- and phosphine-boranes, where the $\mathrm{H}_{2}$ can be 
captured between a boron and a $\pi$-system, for example like in benzyl amineborane. ${ }^{[5]}$ In protonated hydrazine-bisborane negatively charged hydrogen replaces the $\pi$-system. If we compare the interaction in hydrazine-bisborane to the interaction in benzyl amine-borane, we see that the negatively charged $\mathrm{B}-\mathrm{H}$ hydrogen replaces the $\pi$-system. As a result the interaction is stronger and shorter than in the amine complex, electron densities at BCP were 0.023 and 0.015 respectively and distances were $1.74 \AA$ and $2.40 \AA$ respectively. It should be noted that such interactions were not found in protonated trifluoroethyl amine-borane and chloroethyl amine-borane, where chain length would allow similar interactions. ${ }^{[5]}$ It suggests that the second boron plays important role in this tweezer like interaction.

\section{$H_{2}$ release from protonated structures}

Protonated borane complexes contain a weakly bound dihydrogen and to assess the stabilities of the hydrazine-borane species we have calculated the Gibbs free energies for the following $\mathrm{H}_{2}$ dissociation reactions:

$$
\begin{array}{lr}
\mathrm{NH}_{2} \mathrm{NH}_{2} \mathrm{BH}_{2}+\bullet \bullet \mathrm{H}_{2} \rightarrow \mathrm{NH}_{2} \mathrm{NH}_{2} \mathrm{BH}_{2}{ }^{+}+\mathrm{H}_{2} & -20.9 \mathrm{kcal} / \mathrm{mol} \\
\mathrm{H}_{3} \mathrm{BNH}_{2} \mathrm{NH}_{2} \mathrm{BH}_{2}{ }^{+} \bullet \bullet \mathrm{H}_{2} \rightarrow \mathrm{H}_{3} \mathrm{BNH}_{2} \mathrm{NH}_{2} \mathrm{BH}_{2}{ }^{+}+\mathrm{H}_{2} & -27.2 \mathrm{kcal} / \mathrm{mol}
\end{array}
$$

Both reactions are much more exergonic than the analogues reactions for amineboranes and phosphine-boranes. ${ }^{[5,9]}$ The reason can be found in the resulting structures which are presented on Figures 5 and 6.

The dihydrogen release from protonated hydrazine-borane leads to the formation of a positively charged three membered cycle. After the removal of $\mathrm{H}_{2}$ an empty orbital is left on boron and there is a free electron pair on the second nitrogen - an intramolecular Lewis complexation reaction takes place, a cycle is formed and $20.9 \mathrm{kcal} / \mathrm{mol}$ of energy is released. A different kind of cycle forms when $\mathrm{H}_{2}$ is removed from protonated hydrazine-bisborane. In protonated complex the $\mathrm{H}_{2}$ was captured between the negatively charged hydrogen and positive boron $\left(\mathrm{B}-\mathrm{H} \bullet \bullet \mathrm{H}_{2} \bullet \mathrm{B}\right)$, after the dihydrogen release a direct interaction that can be described as a 3-centre- 
2-electron $\mathrm{B}-\mathrm{H}-\mathrm{B}$ bond is formed (the $\mathrm{B}-\mathrm{H}$ distances in this interaction are $1.324 \AA$ and electron densities at the BCP-s are 0.103).

\section{Conclusions}

In this work we presented the gas-phase complexation energies, acidities, basicities, and Gibbs free energy changes for the dihydrogen release reactions from protonated complexes for hydrazine-borane and hydrazine-bisborane. All values were calculated at MP2/6-311+G(d.p) level. The formation of both complexes was energetically favourable - addition of the first $\mathrm{BH}_{3}$ releases $17.1 \mathrm{kcal} / \mathrm{mol}$ and the second addition releases $15.8 \mathrm{kcal} / \mathrm{mol}$. There are two competing deprotonation centres $(\mathrm{N}-\mathrm{H}$ and $\mathrm{B}-\mathrm{H})$ in both complexes. The $\mathrm{N}-\mathrm{H}$ deprotonations are reversible but $\mathrm{B}-\mathrm{H}$ deprotonations are not, leading to intramolecular rearrangements. Although the rearranged results of the $\mathrm{B}-\mathrm{H}$ deprotonations are energetically more favourable, we concluded that the $\mathrm{N}-\mathrm{H}$ deprotonations are more probable to occur. Compared to hydrazine the attachment of $\mathrm{BH}_{3}$ increases the $\mathrm{N}-\mathrm{H}$ acidity by $46.3 \mathrm{kcal} / \mathrm{mol}$. For both complexes the protonation centre is located at the boron moiety. The basicity values found for hydrazine-borane and -bisborane are 180 and $172.8 \mathrm{kcal} / \mathrm{mol}$ respectively. The protonated structure of hydrazine-bisborane is cyclic and can be described as $\mathrm{H}_{2}$ captured between a negatively charged $\mathrm{B}-\mathrm{H}$ hydrogen and positive boron (B$\mathrm{H} \bullet \cdot \mathrm{H} 2 \bullet B$ ). The release of dihydrogen from protonated complexes (Ghydrazine-borane = $20.9 \mathrm{kcal} / \mathrm{mol}$ and Ghydrazine-bisborane $=-27.2 \mathrm{kcal} / \mathrm{mol}$ ) is more exergonic than from amine-boranes. The resulting positively charged structures are cyclic, which is the reason behind the unexpectedly favourable $\mathrm{H}_{2}$ release.

\section{Acknowledgement}

This work was supported by institutional research funding IUT (IUT20-15) of the Estonian Ministry of Education and Research. We acknowledge the Estonian Science Foundation (Grant No. 8809) and the Estonian Ministry of Education and Research Targeted Financing Project No. SF0180120s08. This work is a part of an Integrated Exchange Program 'PARROT' co-financed by the Estonian Science Foundation and the French Ministry of Foreign Affairs. In addition, the work has been 
partially supported by graduate school "Functional materials and technologies" receiving funding from the European Social Fund under project 1.2.0401.09-0079 in Estonia. 


\section{References}

[1] V. J. Goubeau, E. Ricker, Z. Anorg. Allg. Chem. 1961, 310, 123.

[2] N. Vinh-Son, S. Swinnen, M. H. Matus, M. T. Nguyen, D. A. Dixon, Phys. Chem. Chem. Phys. 2009, 11, 6339.

[3] T. Hügle, M. F. Kühnel, D. Lentz, J. Am. Chem. Soc. 2009, 131, 7444.

[4] R. Moury, G Moussa, U. B. Demirci, J. Hannauer, S. Bernard, E. Petit, A. van der Lee, P. Miele, Phys. Chem. Chem. Phys. 2012. 14. 1768.

[5] J.-L.M. Abboud, B. Németh, J.-C. Guillemin, P. Burk, A. Adamson, E.R. Nerut, Chem. Eur. J. 2012, 18, 3981.

[6] G.N. Patwari, J. Phys. Chem. A 2005, 109, 2035.

[7] A. Martín-Sómer, A. M. Lamsabhi, M. Yáñez, J. Z. Dávalos, J. González, R. Ramos, J.-C. Guillemin, Chem. Eur. J. 2012, 18, 15699.

[8] A. Adamson, J.-C. Guillemin, P. Burk, J. Mol. Mod. 2013, 19, 5089.

[9] A. Adamson, P. Burk, Comp. Theor. Chem. 2014, 1032, 12.

[10] S. Mebs, R. Kalinowski, S. Grabowsky, D. Förster, R. Kickbusch, E. Justus, W. Morgenroth, C. Paulmann, P. Luger, D. Gabel, D. Lentz, J. Phys. Chem. A 2011, $115,1385$.

[11] S. Mebs, S. Grabowsky, D. Förster, R. Kickbusch, M. Hartl, L. L. Daemen, W. Morgenroth, P. Luger, B. Paulus, D. Lentz, J. Phys. Chem. A 2010, 114, 10185.

[12] Gaussian 09. Revision A.02. M. J. Frisch, G. W. Trucks, H. B. Schlegel, G. E. Scuseria, M. A. Robb, J. R. Cheeseman, G. Scalmani, V. Barone, B. Mennucci, G. A. Petersson, H. Nakatsuji, M. Caricato, X. Li, H. P. Hratchian, A. F. Izmaylov, J. Bloino, G. Zheng, J. L. Sonnenberg, M. Hada, M. Ehara, K. Toyota, R. Fukuda, J. Hasegawa, M. Ishida, T. Nakajima, Y. Honda, O. Kitao, H. Nakai, T. Vreven, J. A. Montgomery, Jr., J. E. Peralta, F. Ogliaro, M. Bearpark, J. J. Heyd, E. Brothers, K. N. Kudin, V. N. Staroverov, R. Kobayashi, J. Normand, K. Raghavachari, A. Rendell, J. C. Burant, S. S. lyengar, J. Tomasi, M. Cossi, N. Rega, J. M. Millam, M. Klene, J. E. Knox, J. B. Cross, V. Bakken, C. Adamo, J. Jaramillo, R. Gomperts, R. E. Stratmann, O. Yazyev, A. J. Austin, R. Cammi, C. Pomelli, J. W. Ochterski, R. L. Martin, K. Morokuma, V. G. Zakrzewski, G. A. Voth, P. Salvador, J. J. Dannenberg, S. Dapprich, A. D. Daniels, Ö. Farkas, J. B. Foresman, J. V. Ortiz, J. Cioslowski, and D. J. Fox, Gaussian, Inc., Wallingford CT, 2009.

[13] M. Head-Gordon, J. A. Pople, M. J. Frisch, Chem. Phys. Lett. 1988, 153, 503.

[14] S. Saebø, J. Almlöf, Chem. Phys. Lett. 1989, 154, 83. 
[15] M. J. Frisch, M. Head-Gordon, J. A. Pople, Chem. Phys. Lett. 1990, 166, 275.

[16] M. J. Frisch, M. Head-Gordon, J. A. Pople, Chem. Phys. Lett. 1990, 166, 281.

[17] M. Head-Gordon, T. Head-Gordon, Chem. Phys. Lett. 1994, 220, 122.

[18] D. McLean, G. S. Chandler, J. Chem. Phys. 1980, 72, 5639.

[19] K. Raghavachari, J. S. Binkley, R. Seeger, J. A. Pople, J. Chem. Phys. 1980, 72, 650.

[20] R. C. Binning Jr., L. A. Curtiss, J. Comp. Chem. 1990, 11, 1206.

[21] M. J. Frisch, J. A. Pople, J. S. Binkley, J. Chem. Phys. 1984, 80, 3265.

[22] S. F. Boys, F. Bernardi, Mol. Phys. 1970, 19, 553.

[23] R. F. W. Bader, Atoms in Molecules: A Quantum Theory. Oxford University Press. Oxford. 1990.

[24] T. A. Keith, AIMAll. Version 11.04.03. (aim.tkgristmill.com).

[25] S. M. Bachrach, Population analysis and electron densities from quantum mechanics, in Reviews in computational chemistry. vol 5. (Eds. K. B. Lipkowitz, D. B. Boyd) John Wiley \& Sons. Inc. 2007 DOI: 10.1002/9780470125823.ch3

[26] J. Meister, W. H. E. Schwarz, J. Phys. Chem. 1994, 98, 8245.

[27] H. Anane, S. El Houssame, A. El Guerraze, A. Guermoune, A. Boutalib, A. Jarid, I. Nebot-Gil, F. Tomás, Cent. Eur. J. Chem. 2008, 6, 400.

[28] H. Anane, S. El Houssame, A. El Guerraze, A. Jarid, A. Boutalib, I. Nebot-Gil, F. Tomás, J. Mol. Struct. (Theochem), 2004, 709, 103. 
Table 1. Comparison of different acidity centres in hydrazine-borane and hydrazinebisborane. The acidity centres on hydrazine-borane are numbered as follows (in superscript): $\mathrm{N}^{2} \mathrm{H}_{2} \mathrm{~N}^{1} \mathrm{H}_{2}-\mathrm{BH}_{3}$.

\begin{tabular}{lccccc}
\multicolumn{2}{c}{ Deprotonation centre } & $\mathbf{H}$ (Hartree) & $\mathbf{G}$ (Hartree) & $\begin{array}{c}\Delta \mathbf{G} \\
\text { (kcal/mol) }\end{array}$ & $\begin{array}{c}\text { GA } \\
\text { (kcal/mol) }\end{array}$ \\
\hline Hydrazine-borane & $\mathrm{B}$ & $-137,540835$ & $-137,577417$ & 0,0 & 310,4 \\
& $\mathrm{~N} 1$ & $-137,487437$ & $-137,518151$ & 37,2 & 347,6 \\
& $\mathrm{~N} 2$ & $-137,452501$ & $-137,483756$ & 58,8 & 369,2 \\
\hline Hydrazine-bisborane & $\mathrm{B}$ & $-164,094824$ & $-164,135515$ & 0,0 & 285,2 \\
& $\mathrm{~N} 1$ & $-164,042469$ & $-164,077531$ & 36,4 & 321,6 \\
\hline H - enthalpy of the deprotonated structure; G - free energy of the protonated structure; $\Delta \mathrm{G}$ \\
gap compared to the most stable structure; GA - gas-phase acidity calculated using the \\
given deprotonation centre.
\end{tabular}


Table 2. The NBO charges on neutral, deprotonated (both B-H deprotonation resulting in "broken" structure and "regular" $\mathrm{N}-\mathrm{H}$ deprotonation), and protonated complexes calculated with MP2/6-311+G(d,p).

\begin{tabular}{|c|c|c|c|c|c|c|c|c|c|c|}
\hline & \multicolumn{2}{|c|}{ Hydrazine } & \multicolumn{4}{|c|}{ Hydrazine-Borane } & \multicolumn{4}{|c|}{ Hydrazine-Bisborane } \\
\hline & Neutral & Deprot. & Neutral & $\begin{array}{c}\text { B-H } \\
\text { deprot. }\end{array}$ & $\begin{array}{c}\text { N-H } \\
\text { deprot. }\end{array}$ & Protonated & Neutral & $\begin{array}{c}\text { B-H } \\
\text { deprot. }\end{array}$ & $\begin{array}{c}\mathrm{N}-\mathrm{H} \\
\text { deprot. }\end{array}$ & Protonated \\
\hline B & - & - & -0.033 & $0.391^{\mathrm{a}}$ & -0.008 & 0.171 & -0.042 & $0.509^{\mathrm{a}}$ & -0.023 & 0.111 \\
\hline H & - & - & -0.089 & $-0.194^{a}$ & -0.140 & 0.016 & -0.101 & $-0.150^{a}$ & -0.122 & 0.005 \\
\hline H & - & - & -0.096 & $-0.205^{a}$ & -0.148 & 0.191 & -0.078 & $-0.160^{\mathrm{a}}$ & -0.129 & $0.179^{c}$ \\
\hline H & - & - & -0.110 & - & -0.188 & 0.000 & -0.101 & - & -0.112 & 0.020 \\
\hline H & - & - & - & - & - & 0.198 & - & - & - & $0.260^{c}$ \\
\hline $\mathbf{N}$ & -0.655 & -0.754 & -0.525 & $-1.264^{a}$ & -0.718 & -0.576 & -0.499 & $-1.084^{a}$ & -0.531 & -0.551 \\
\hline H & 0.336 & 0.274 & 0.390 & $0.441^{b}$ & 0.274 & 0.426 & 0.410 & $0.471^{\mathrm{a}}$ & 0.371 & 0.449 \\
\hline H & 0.319 & 0.274 & 0.376 & $0.296^{a}$ & - & 0.407 & 0.410 & $0.373^{a}$ & 0.371 & 0.436 \\
\hline $\mathbf{N}$ & -0.655 & -1.034 & -0.617 & $-1.094^{b}$ & -0.669 & -0.584 & -0.499 & $-1.115^{b}$ & -0.679 & -0.505 \\
\hline H & 0.336 & 0.240 & 0.368 & $0.315^{b}$ & 0.301 & 0.375 & 0.410 & $0.317^{b}$ & 0.324 & 0.427 \\
\hline H & 0.319 & - & 0.338 & $0.313^{b}$ & 0.296 & 0.378 & 0.410 & $0.317^{b}$ & - & 0.426 \\
\hline B & - & - & - & - & - & - & -0.042 & $-0.015^{b}$ & -0.032 & -0.020 \\
\hline H & - & - & - & - & - & - & -0.101 & $-0.150^{b}$ & -0.145 & -0.095 \\
\hline H & - & - & - & - & - & - & -0.078 & $-0.164^{b}$ & -0.122 & -0.036 \\
\hline H & - & - & - & - & - & - & -0.101 & $-0.150^{b}$ & -0.172 & -0.105 \\
\hline
\end{tabular}




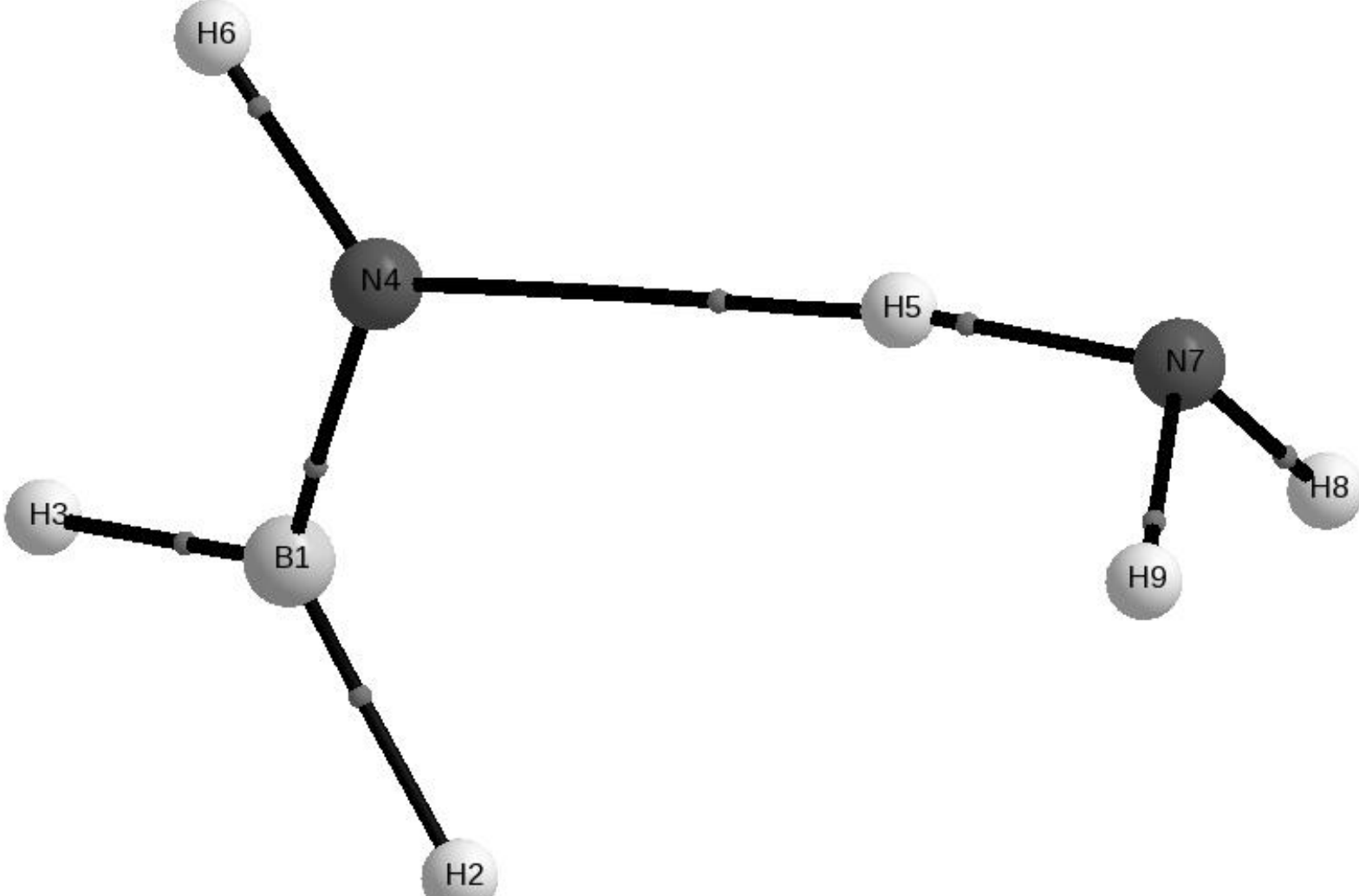

Figure 1. Optimized structure resulting from B-H deprotonation of hydrazine-borane 


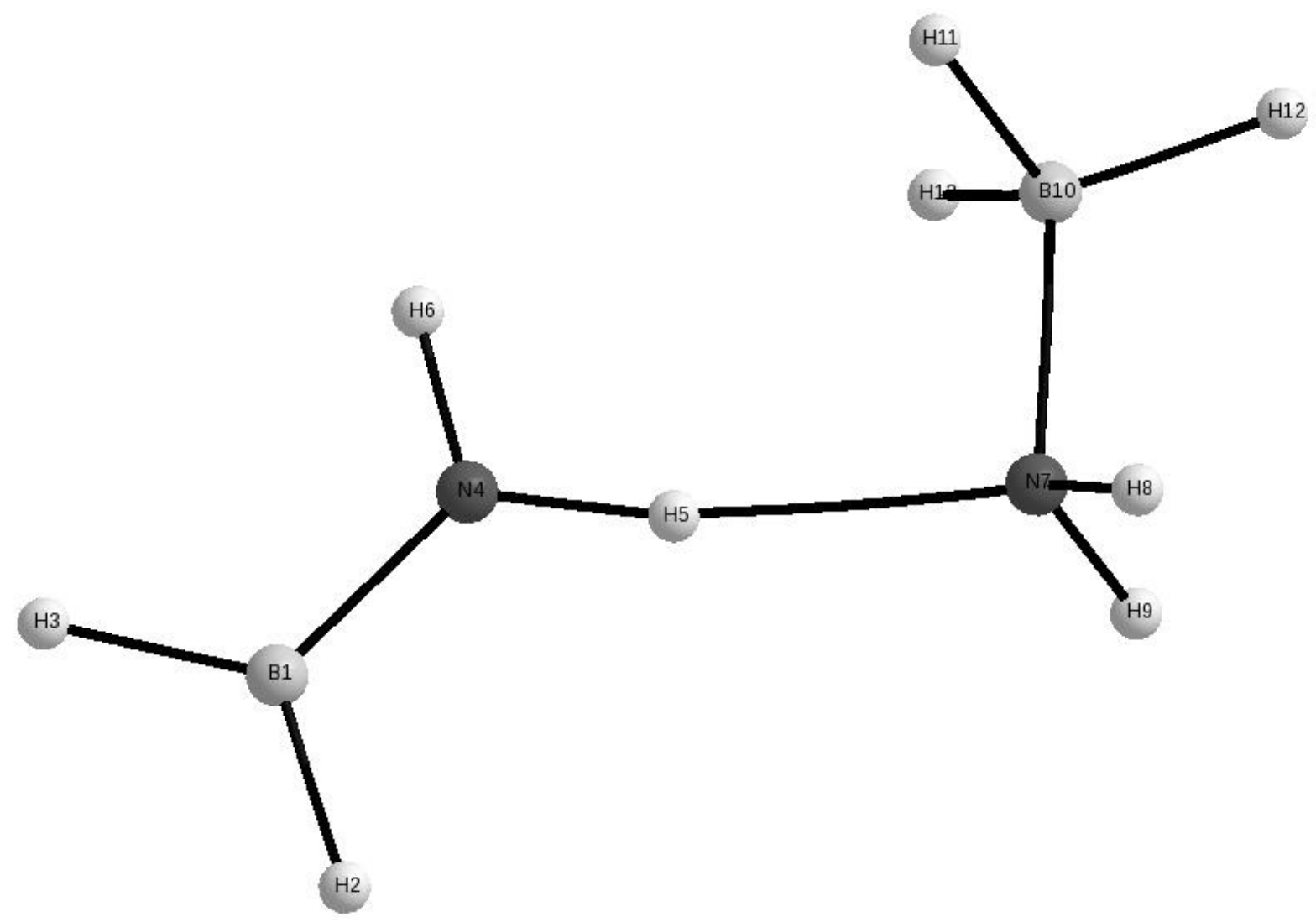

Figure 2. Optimized structure resulting from B-H deprotonation of hydrazine-bisborane 


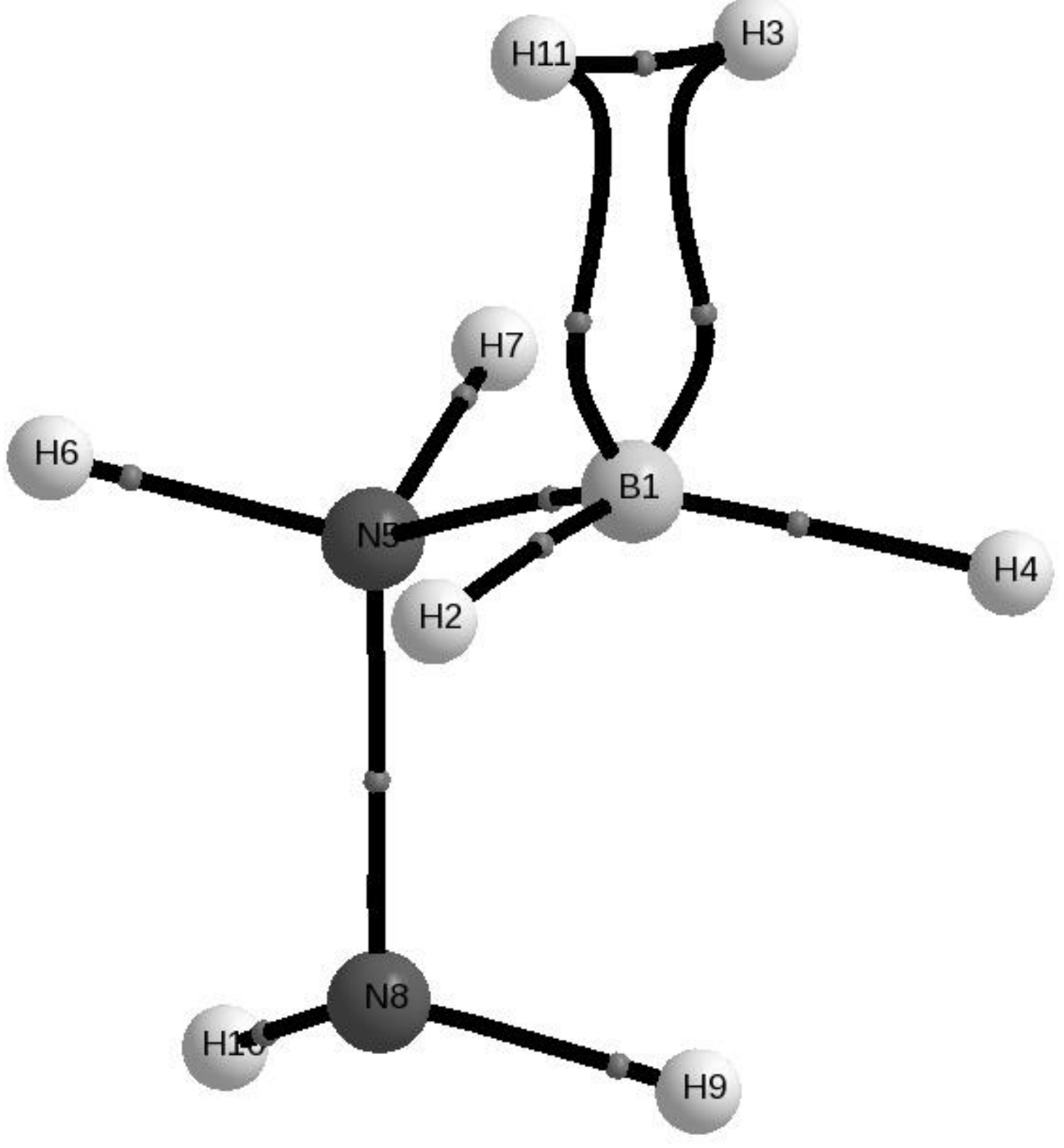

Figure 3. Protonated hydrazine-borane 


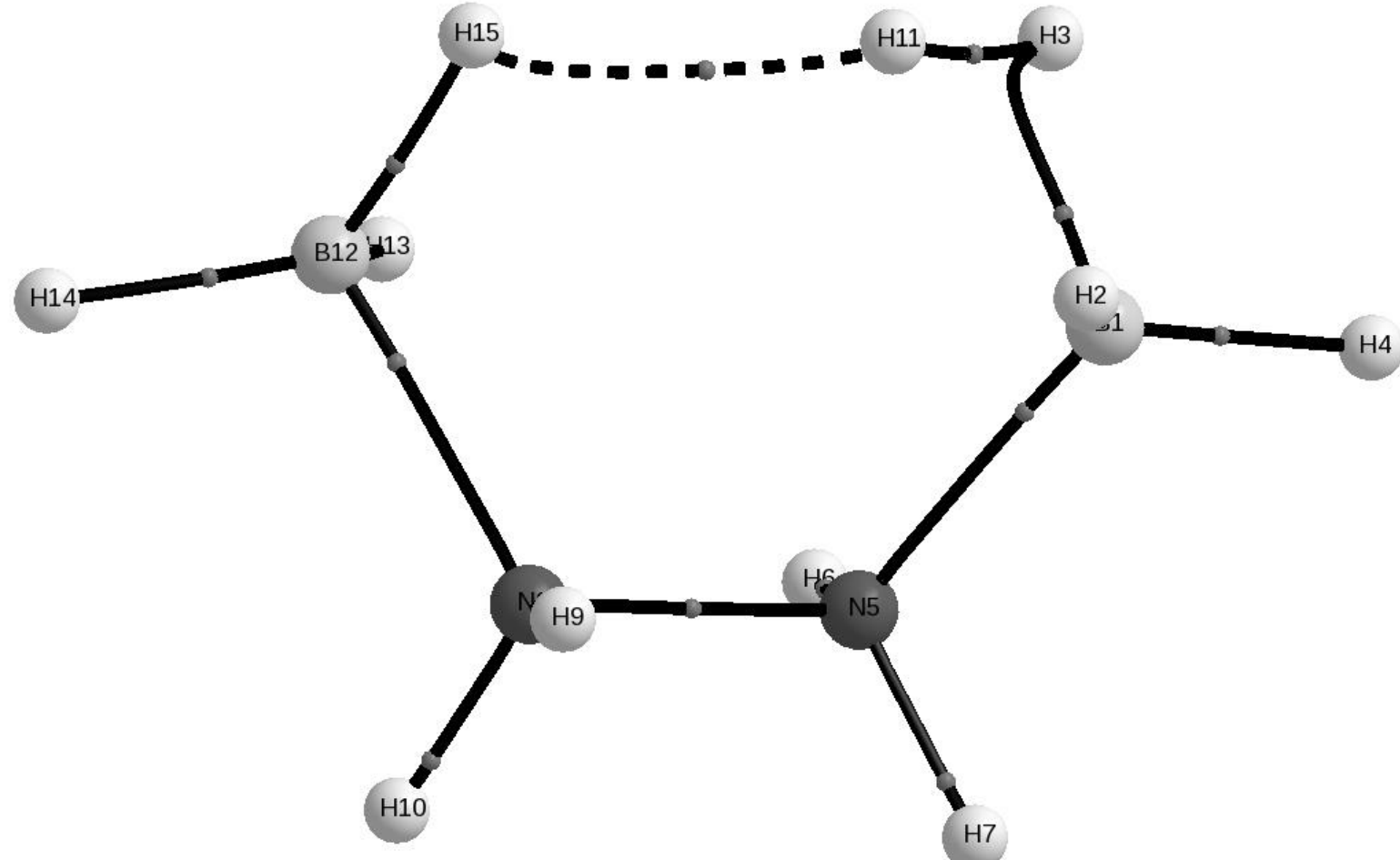

Figure 4. Protonated hydrazine-bisborane 


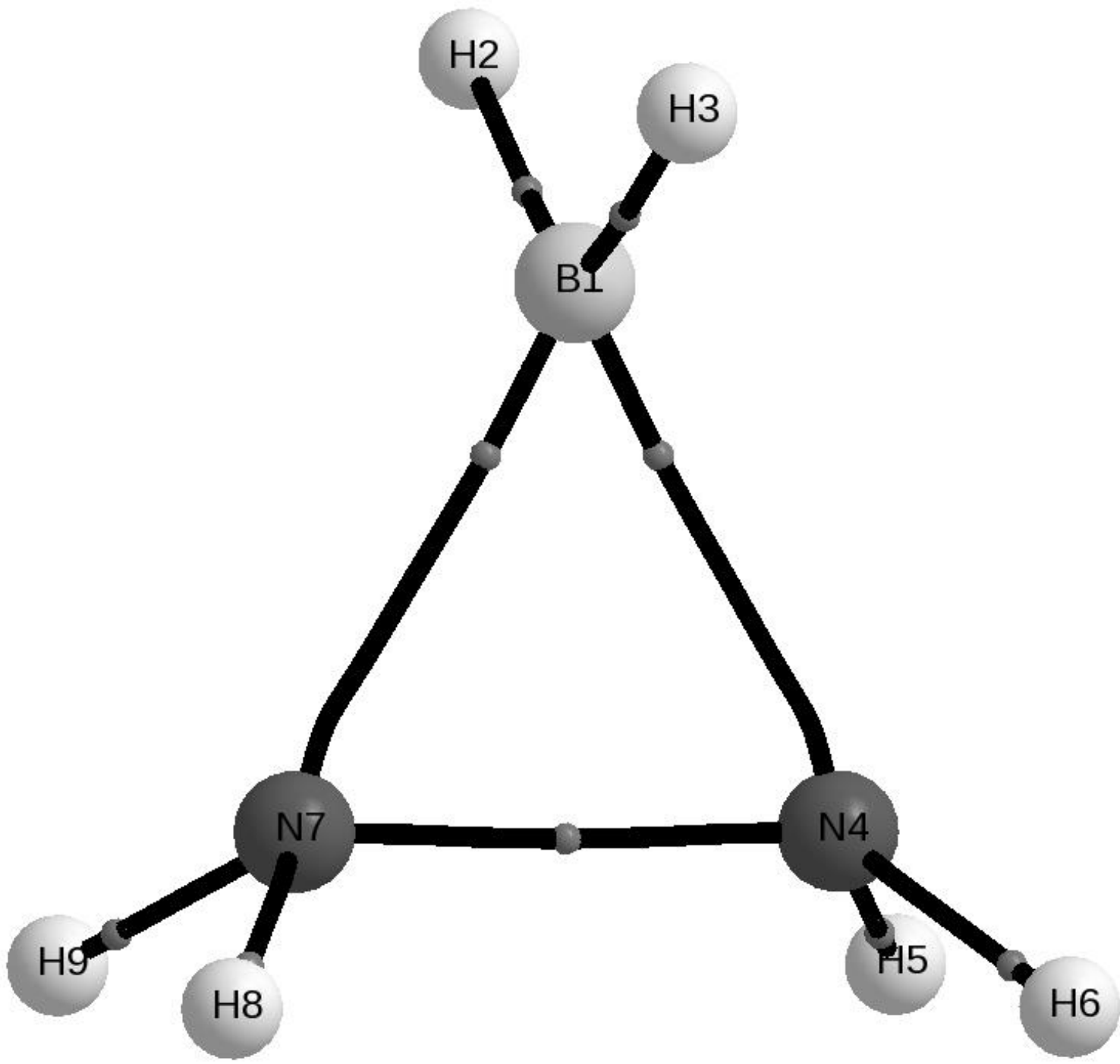

Figure 5. Product of the protonation of hydrazine-bisborane after $\mathrm{H} 2$ release 


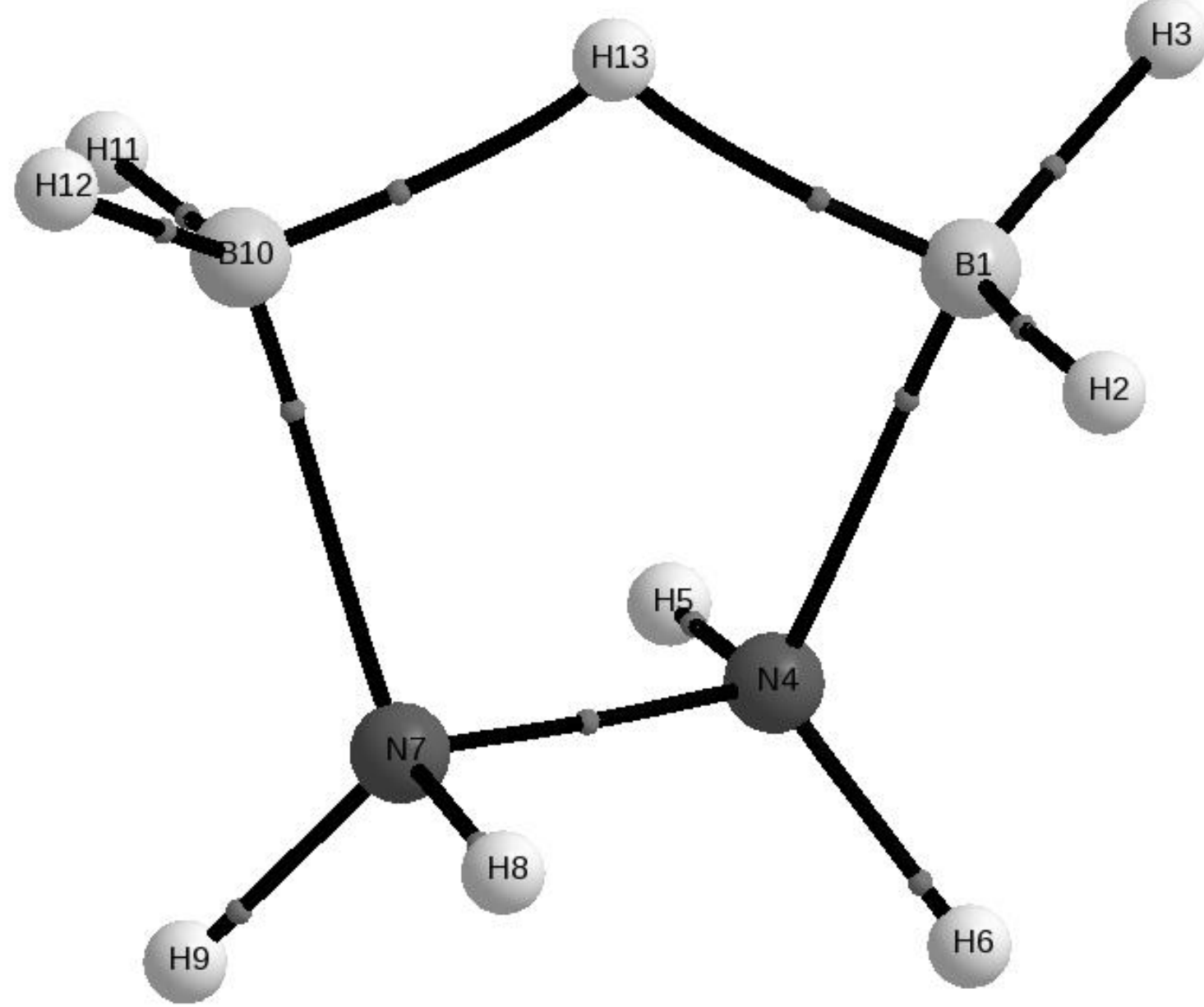

Figure 6. Protonated hydrazine-bisborane after $\mathrm{H} 2$ release 